\title{
Voluntary euthanasia under control? Further empirical evidence from the Netherlands
}

Henk Jochemsen and John Keown Lindeboom Institute for Medical Ethics, the Netherlands and University of Cambridge, respectively

\begin{abstract}
Nineteen ninety-six saw the publication of a major Dutch survey into euthanasia in the Netherlands. This paper outlines the main statistical findings of this survey and considers whether it shows that voluntary euthanasia is under effective control in the Netherlands. The paper concludes that although there has been some improvement in compliance with procedural requirements, the practice of voluntary euthanasia remains beyond effective control.
\end{abstract}

(Fournal of Medical Ethics 1999;25:16-21)

Keywords: Euthanasia; the Netherlands; regulation; slippery slope

\section{Introduction}

Worldwide, the euthanasia debate continues to intensify. In 1997, the Australian parliament voted to repeal euthanasia legislation in the Northern Territory and the US Supreme Court upheld the constitutionality of legislation prohibiting "physician-assisted suicide". In deciding whether euthanasia or assisted suicide should be permitted in principle, and whether they can be controlled in practice, the experience of the Netherlands, where they have been officially tolerated and widely practised for well over a decade, is clearly of profound importance.

Nineteen ninety-one saw the publication of the results of an important survey, by Professor PJ van der Maas, into end-of-life decision making by Dutch doctors in the year $1990 .{ }^{2}$ Despite claims to the contrary by supporters of Dutch euthanasia, this survey helped to cast serious doubt on Dutch claims that their guidelines were sufficiently strict effectively to control the practice of voluntary euthanasia (the intentional termination of patients' lives at their request) and to prevent non-voluntary euthanasia (the intentional termination of the lives of patients incapable of making a request).

The survey disclosed the widespread practice of non-voluntary euthanasia; the use of euthanasia even when doctors thought that palliative care was a viable alternative, and the common practice bo doctors of illegally certifying euthanasia deaths ajं deaths by "natural causes" instead of reporting them, as required by the guidelines, to the authorities. $^{3}$

In 1996, Van der Maas and Van der Wa@ published the results of an extensive survey int@ end-of-life decisions by Dutch doctors in the year 1995. ${ }^{4}$ Do the results of this survey show anfo improvement in the degree of control over euthas nasia?

\section{The survey}

The survey sought particularly to ascertain the incidence of intentional life-shortening by doc $\overrightarrow{0}$ tors; the extent to which they complied with theip duty to report such cases (in accordance with procedure dating from late 1990 which was giver? statutory force in June 1994), and the quality of their reporting. The main purpose of the report $\Phi$ ing procedure is to provide for possible scrutiny of the intentional termination of life by doctors an to promote careful decision making in such cases. $\frac{9}{3}$ The most important quantitative data generate by the survey are reproduced in table 1 .

Before the figures are analysed, it is importang to note that the only objectively verifiable figure are those concerning the total number of deaths and the total number of cases reported. All the other figures are based on the responses of the physicians concerning cases in which they said they had recently been involved.

It is no less important to stress that this papeñ does not question the methodology used by the ${ }^{+}$ researchers to obtain their data, namely, inter views with 405 physicians and postal question $\overrightarrow{\mathrm{D}}^{+}$ naires mailed to physicians who had attende $\mathbb{P}$ 6,060 deaths identified from death certificates. We use the researchers' own data and standardly cit their "best estimate" (though in some cases num8 bers have been arrived at on the basis of percent? ages and numbers used in the survey and, in suct cases, we have rounded off the number arrived at)? 
Table 1 End-of-life decisions by doctors in the Netherlands 1990-1995

\begin{tabular}{lrr}
\hline & 1990 & 1995 \\
\hline Deaths in the Netherlands & $129000(100 \%)$ & $135500(100 \%)$ \\
Requests for euthanasia & $8900(7 \%)$ & $9700(7.1 \%)$ \\
Euthanasia & $2300(1.8 \%)$ & $3200(2.4 \%)$ \\
Assisted suicide & $400(0.3 \%)$ & $400(0.3 \%)$ \\
Life-terminating acts without explicit request & $1000(0.8 \%)$ & $900(0.7 \%)$ \\
Intensification of pain and symptom treatment & $22500(17.5 \%)$ & $20000(14.8 \%)$ \\
a. Explicitly intended to shorten life & $1350(1 \%)$ & $2000(1.5 \%)$ \\
b. Partly intended to shorten life & $6750(5.2 \%)$ & $2850(2.1 \%)$ \\
c. Taking into account the probability that life will be shortened & $14400(11.3 \%)$ & $15150(11.1 \%)$ \\
Withdrawal/withholding treatment (incl tube-feeding) & $22500(17.5 \%)$ & $27300(20.1 \%)$ \\
a. At the explicit request of the patient & $5800(4.5 \%)$ & $5200(3.8 \%)$ \\
b. Without the explicit request of the patient & & \\
b1. Explicitly intended to shorten life & $2670(2.1 \%)$ & $14200(10.5 \%)$ \\
b2. Partly intended to shorten life & $3170(2.5 \%)$ & - \\
b3. Taking into account the probability that life will be shortened & $10850(8.4 \%)$ & $7900(5.8 \%)$ \\
Intentional termination of neonates & - & 10.00 \\
a. Without withholding/withdrawing treatment & - & 80.00
\end{tabular}

In other words, our paper does not take issue with the researchers' methodology but with their interpretation of the statistics it generated.

A final preliminary point is that the Dutch adopt a particularly narrow definition of "euthanasia" as the intentional shortening of a patient's life at the patient's explicit request. In other words, "euthanasia" in the Netherlands means "active, voluntary euthanasia" and does not include intentional life-shortening by omission ("passive euthanasia") or euthanasia without the patient's request (whether non-voluntary if the patient is incompetent or involuntary if the patient is competent.) For ease of exposition, the Dutch definition is followed here unless the contrary is apparent.

\section{EUTHANASIA AND ASSISTED SUICIDE}

Between 1990 and 1995 the number of requests for euthanasia increased, as did the number of requests granted. ${ }^{6}$ Cases of euthanasia and assisted suicide rose from 2,700 cases in 1990 to 3,600 in 1995 , or from $2.1 \%$ to $2.7 \%$ of all deaths.

According to the attending physicians, there were treatment alternatives in $17 \%$ of these cases but in almost all the patients did not want them. ${ }^{7}$ However, in 1994, the Dutch Supreme Court held that doctors should not hasten death whenever the alternative of palliative treatment was available, at least in cases of mental suffering ${ }^{8}$ and the ministers of justice and health, ${ }^{9}$ and the Royal Dutch Medical Association (KNMG), ${ }^{10}$ have decided that the same restriction should apply in cases of somatic suffering. The above cases appear, therefore, to have breached this guideline.

Life was shortened by one to four weeks in $31 \%$ of euthanasia cases and $45 \%$ of assisted suicides and by more than a month in $7 \%$ of cases of euthanasia and in $30 \%$ of assisted suicides. ${ }^{11}$

Physicians stated that the main reason why patients requested euthanasia was "intolerable suffering without prospect of improvement" $(74 \%),{ }^{12}$ which has become the standard terminology to describe the seriousness of the condition required by the law. But the next most common reasons were "to prevent loss of dignity" (56\%) and "to prevent further suffering" ( $47 \%$ ). It must surely be doubted whether either of these reasons, by itself, satisfies the requirement of unbearable suffering.

Interestingly, one of the most important reasons for rejecting a request for euthanasia (cited by $35 \%$ of physicians) was the physician's opinion that the patient's suffering was not intolerable. ${ }^{13}$ This suggests that, despite the emphasis placed by the advocates of euthanasia on patient autonomy, the application of euthanasia is more a function of the physican's judgment about the quality of the patient's life than of respect for the patient's autonomy. This suggestion is fortified by the evidence about the extent to which Dutch doctors continue to terminate the lives of patients without an explicit request.

\section{LIFE-TERMINATING ACTIONS WITHOUT EXPLICIT REQUEST}

The survey confirms that the intentional shortening of patients' lives without explicit request remains far from uncommon. Nine hundred patients had their lives ended without explicit request in 1995, representing $0.7 \%$ of all deaths, only a slight decrease on the $0.8 \%$ so terminated in $1990 .{ }^{14}$ In other words, of the 4,500 $(3,200+$ $400+900)$ cases in which doctors admitted they 
actively and intentionally terminated life, one in five involved no explicit request.

The main reason for not discussing the issue with the patient was stated to be the patient's incompetence (due, for example, to dementia). But not all patients whose lives were terminated without an explicit request were incompetent. In $15 \%$ of cases where no discussion took place but could have, the doctor did not discuss the termination of life because the doctor thought that the termination of the patient's life was clearly in the patient's best interests. ${ }^{15}$

Furthermore, in a third of the 900 cases, there had been a discussion with the patient about the possible termination of life, and some $50 \%$ of these patients were fully competent, yet their lives were terminated without an explicit request. .t $^{\text {th }}$

Moreover, in $17 \%$ of the 900 cases, treatment alternatives were thought to be available by the attending physician. ${ }^{17}$

The physicians thought that life was shortened by one to four weeks in 3\% of cases but by more than a month in $6 \% .{ }^{18}$ Finally, physicians had not discussed their action with a colleague in $40 \%$ of cases, with a close relative in $30 \%$ of cases, and with anyone at all in $5 \% .{ }^{19}$

\section{INTENSIFICATION OF PAIN ANI) SYMPTOM} TREATMENT

In 20,000 cases (according to the physician interviews) or 25,800 cases (according to the death certificate survey), palliative drugs were administered in doses which almost certainly shortened life. In some 2,000 of these cases the doctor explicitly intended, and in a further 2,850 cases, partly intended, to shorten life..$^{20}$ The researchers estimate that the grey area between intending to alleviate pain and symptoms and intending to shorten life is about $2 \%$ of all deaths, the same as in $1990 .^{21}$

Where doctors administered palliative drugs partly in order to shorten life, they had discussed it with the patient in just over half of the cases $(52 \%)$ and in only $36 \%$ of the cases was there an explicit request for life-shortening doses by the patient. The physicians stated that 86 patients (3\%) with whom they had not discussed this treatment were fully competent. ${ }^{22}$ Moreover, in only $36 \%$ of the cases had the doctors consulted a colleague. Life was shortened by an estimated one to four weeks in $7 \%$ of cases but by more than a month in $1 \% .^{23}$

\section{WITHHOLDING/WITHIRAWING TREATMENT}

In some 27,300 cases a treatment was withheld or withdrawn (in 5,200 cases at the patient's explicit request) taking into account a probable shortening of life.
However, in 18,000 of these cases $(14,200$ def which involved no explicit request by the patient it was the physician's explicit intention to shorte? life (though the survey does not state in how man cases the treatment was disproportionate, i which case doctors could, had they wished, hav properly withdrawn it for that reason and withoum intending to shorten life. ${ }^{24}$ )

In the majority of cases in which no discussion.

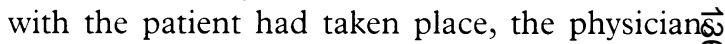
stated that the patient was either incompetent of only partly competent. However, in $1 \%$ of thes $\widehat{\Phi}$ cases (140 patients) the physician considered the patient fully competent. ${ }^{25}$

In cases where treatment was withheld or with $\vec{\oplus}$ drawn with the explicit intent to shorten life, the physician estimated that life was shortened by one to seven days in $34 \%$ of cases, by one to four week in $18 \%$ and by more than a month in $9 \% .^{2 n}$

5. NEONATES

The survey reports that over 1,000 newborns dif in the Netherlands before their first birthday and estimates that the lives of about 15 are actively an\& intentionally terminated by doctors. ${ }^{2 \pi}$ The figur of 15 seems, however, a significant underestimat

The survey shows that in ten cases $(1 \%)$ doctor administered a drug with the explicit intention of shortening life. But it also reveals a further $8 \overline{\mathcal{Q}}$ cases in which, also with the explicit intention 喷 shortening life, doctors administered a drug and withdrew or withheld a life-prolongin $\overline{\mathrm{g}}$ treatment..$^{2 *}$ In total, therefore, it appears to have been the explicit intention of doctors to shorte? the lives of 90 neonates, not $15 .^{24}$

Moreover, in no fewer than $41 \%$ of the $1,00 \%$ cases, treatment was withdrawn or withheld wit? the explicit intention of shortening life. In 8 significant proportion of these cases, life was. terminated because the babies' lives were not thought bearable. Forty-five per cent of thes\& babies were expected to live more than four weeks్ and some of them more than half a year. ${ }^{30}$

In around a fifth of cases in which doctors intentionally withheld or withdrew treatment wit the explicit purpose of shortening life because the baby's life was thought unbearable, there had beeñ no discussion with the parents. ${ }^{31}$ Doctors said tha嵒 in most cases this was because the situation was $\mathrm{s} Q$ clear that discussion was unnecessary or becaus $\mathbb{Q}$ there was no time, though these reasons are n⿺廴 elaborated.

Finally, doctors reported hardly any cases of the intentional shortening of neonatal life to the authorities. 
6. ASSISTED SUICIDE OF PSYCHIATRIC PATIENTS

Based on the replies of psychiatrists in respect of the year 1995, the survey estimates that although some 320 psychiatric patients explicitly request assistance in suicide annually, only two to five are assisted to commit suicide by psychiatrists. Among psychiatrists who would never grant a request for assisted suicide on the basis of mental suffering (almost 1/3 of the respondents) "professional opinion" was cited by $88 \%$ as the most important reason. Only $2 \%$ of psychiatrists had ever assisted suicide. ${ }^{32}$

This relatively restrictive approach of psychiatrists may owe not a little to the controversy generated by the case of Dr Chabot, a psychiatrist criticised by a medical disciplinary court for assisting in the suicide of a 50-year-old woman who suffered grief after the loss of her two sons. ${ }^{33}$

Disclosing statistics which support a restrictive approach, the survey also indicates that of those patients not assisted in suicide, $16 \%$ committed suicide without assistance by a physician and that, of those patients still living, 35\% no longer wished for death and that the death wish in a further $10 \%$ had diminished.

\section{CONSULTATION}

The guidelines for permissible euthanasia and assisted suicide require the doctor, before agreeing to either, to engage in a formal consultation (consultatie), and not merely an informal discussion (overleg), with a colleague.

In cases of euthanasia and assisted suicide $92 \%$ of doctors had, according to the survey, discussed the case with a colleague. ${ }^{34}$ In $13 \%$ of these cases, however, the discussion did not amount to a formal consultation. Consultation took place, therefore, in $79 \%$ of cases. However, other figures in the survey suggest that consultation occurred in a significantly smaller percentage of cases. For the survey indicates that consultation occurred in $99 \%$ of reported cases but in only $18 \%$ of unreported cases $^{35}$ and that almost $60 \%$ of all cases of euthanasia and assisted suicide were not reported, ${ }^{36}$ from which it seems that consultation occurred in only around half of all cases. ${ }^{37}$

In the cases of life-termination without explicit request, a discussion occurred in $43 \%$ of cases but in $40 \%$ this did not amount to consultation. Consequently, there was no consultation in $97 \%$ of such cases.

Moreover, even when consultation did take place, it was usually with a physician living locally and the most important reasons given for consulting such a physician were his views on life-ending decisions and his living nearby: expertise in palliative care was hardly mentioned. Further, in the overwhelming majority of cases, the first doctor had made his mind up before consulting and the doctor consulted disagreed in only $7 \%$ of cases. ${ }^{38}$ In short, the requirement of consultation, even when it is satisfied, hardly operates as a rigorous check on decision making.

\section{REPORTING}

In $199541 \%$ of cases of euthanasia and assisted suicide were reported to the local medical examiner, as required by the reporting procedure. While this is an improvement on the figure of $18 \%$ reported in 1990, it means that a clear majority of cases, almost $60 \%$, still go unreported. Moreover, the survey confirms that the legal requirements are breached more frequently in unreported cases, in which there is less often a written request by the patient, a written record by the doctor, or consultation by the doctor. ${ }^{39}$

The most important reasons given by doctors for failing to report in 1995 were (as in 1990), the wish to avoid the inconvenience (for the doctor and/or the relatives) of an investigation by the authorities, and to avoid the risk of prosecution (though, as the consistently tiny number of prosecutions indicates, this risk is negligible). Thirty per cent of doctors stated that they did not report because they had failed to observe the requirements for permissible euthanasia and $12 \%$ because they considered euthanasia was a private matter between doctor and patient. ${ }^{40}$

\section{Discussion}

The second survey confirms at least three disturbing findings of the first survey.

1. INCIDENCE OF INTENTIONAL LIFE-SHORTENING WITH AND WITHOUT EXPLICIT REQUEST

Like the first survey, the second indicates a sizeable incidence of intentional life-shortening by Dutch doctors. Even adopting the unusually narrow Dutch definition of euthanasia as active, voluntary euthanasia there were no fewer than 3,200 cases in 1995 (2.4\% of all deaths), an increase of almost a thousand on the 1990 total of 2,300 ( $1.8 \%$ of all deaths).

But if all cases in which doctors explicitly intended to shorten life (whether by act or omission, and whether with or without the patient's request) are included, the total rises steeply. Adding the cases of assisted suicide (400); life-termination without explicit request (900) and the intensification of pain and symptom treatment with the explicit intent to shorten life $(2,000)$, the total more than doubles from 3,200 to 6,500 .

And if to this number are added the cases of withholding or withdrawing treatment with the explicit intent to shorten life $\left(18,000^{41}\right)$; cases in 
which neonates were intentionally terminated (90 cases) and psychiatric patients assisted in suicide (two to five cases), the total rises to over 24,500 cases.

\section{EUTHANASIA AS AN ALTERNATIVE TO PALLIATIVE CARE}

The survey's comment that "the quality of medical treatment near the end of life has improved"42 might not unreasonably be thought to display a certain complacency, particularly in a country which has some way to go in the provision of adequate palliative care. The high incidence of intentional life-shortening disclosed by the survey and the relative weakness of the reasons for euthanasia given in many cases by the doctors tend to suggest that euthanasia is not confined to cases of "last resort" and is at least sometimes used as an alternative to palliative care. The case of $\mathrm{Dr}$ Chabot, in which the defendant doctor assisted a grieving woman, whom he did not consider to be physically or mentally ill, to kill herself, and in which the Supreme Court held that such suffering could indeed justify assisted suicide, illustrates the elasticity of the requirement of "unbearable suffering".

The survey confirms that, even when doctors believe that treatment alternatives are available, they not infrequently resort to euthanasia. The opinion of the Supreme Court, the ministers of justice and health, and the KNMG, that euthanasia is impermissible when treatment alternatives are available, even if the patient refuses them, has clearly not prevented its administration in such circumstances. In a move that would make the prospect of prosecution even more remote, the then minister of justice appeared to reverse her earlier position and instructed the attorneys general that the refusal by the patient of available treatment alternatives does not render euthanasia unlawful. ${ }^{43}$

\section{WIDESPREAD BREACH OF THE REQUIREMENT TO} REPORT

Although $41 \%$ of cases $(1,466)$ were reported in 1995 as opposed to $18 \%$ (486) in 1990 , it remains true that in both years, as in every year in between, a clear majority of cases has gone unreported. There was, in short, no official control whatever over the majority of cases of euthanasia, assisted suicide or the termination of life without explicit request.

Nor should the alleged increase in reporting be accepted uncritically. First, the second survey records an increase in cases of euthanasia between 1990 and 1995 (900 cases) almost as large as the increase in cases reported ( 980 cases). Secondly, if the total of 6,500 cases of active, intentional life-shortening is used, then the proportion of unreported cases rises from $59 \%$ to $77 \%$. On the total of 24,500 cases, the proportion unreporte of reaches $94 \%$.

It will be recalled that the purpose of the reporting procedure is to allow for scrutiny of th $\overline{\mathrm{D}}$ intentional termination of life by doctors and tQ promote observance of the legal and professionap requirements for euthanasia. The undisputed facP that a clear majority of cases $(59 \%$ according t $\vec{\omega}$ the survey, at least $77 \%$ on our calculations) stil goes unreported, serves only to reinforce doubts about the ability of the procedure to fulfil its puri pose and to undermine Dutch claims of effectiver regulation, scrutiny and control. Further, even those cases which are reported are reported by the doctor, and one may wonder whether the doctor's report is any more likely to disclose evidence of $\overrightarrow{f_{n}}$ wrongdoing than is a tax return to disclose evidence of undeclared earnings.

\section{Conclusions}

With the publication of the first Van der Maaș survey in 1991 it became clear that the so-called "strict safeguards" laid down in 1984 by the courts and the Royal Dutch Medical Association had largely failed. The survey cast doubt on cen $\frac{\sigma}{2}$ tral assurances which had been given by the advo $\mathbb{D}$ cates of voluntary euthanasia: that euthanasio would be performed only at the patient's explicio request and that doctors terminating life withou年 request would be prosecuted for murder; thap. euthanasia would be used only in cases of "lass, resort" and not as an alternative to palliative care ${ }_{z}^{\bar{\Phi}}$ and that cases would be openly reported and duly scrutinised. The Dutch reaction to the survey's findings was also revealing: the cases of non? voluntary euthananasia it disclosed, far from being criticised, were largely condoned. In short the survey indicated that, in less than a decade, the Dutch had slid down the slippery slope.

It is therefore surprising that an Americap commentator should observe that the similarity between the findings in respect of 1990 and $199 \mathrm{~s}$ shows that the Dutch are apparently not descend? ing a slippery slope.$^{44}$ This observation quite overe looks the fact that the first survey showed that th descent had already occurred by 1990: the second survey, far from showing that there has been no descent from 1984 to 1995 shows merely tha there has been no significant ascent from 1990 to 1995.

The second survey is little more reassuring thar the first. Dutch proponents of voluntary euthana sia claimed that tolerating voluntary euthanasia subject to "safeguards", would allow it to be. "brought into the open" and effectively control? 
led. As the valuable surveys by Van der Maas and Van der Wal disclose, and as several expert commentators have now concluded, ${ }^{45}$ the reality is that a clear majority of cases of euthanasia, both with and without request, go unreported and unchecked. ${ }^{46}$ In the face of the undisputed fact that in a clear majority of cases there is not even an opportunity for official scrutiny, Dutch claims of effective regulation ring hollow.

\section{Henk fochemsen, PhD, is Director of the Lindeboom Institute for Medical Ethics. Fohn Keown, DPhil, is University Lecturer in the Law and Ethics of Medicine in the Faculty of Law, University of Cambridge.}

\section{References and notes}

1 Washington $v$ Glucksberg (1997) 117 S Ct 2258; Vacco $v$ Quill (1997) 117 S Ct 2293.

2 Maas PJ van der et al. Medische beslissingen rond het levenseinde. 's-Gravenhage: SDU Uitgeverij Plantijnstraat, 1991 (published in translation as Euthanasia and other medical decisions concerning the end of life. Amsterdam: Elsevier, 1992).

3 See for example Jochemsen H. Euthanasia in Holland: an ethical critique of the new law. Fournal of Medical Ethics 1994;20:212; Keown J. Euthanasia in the Netherlands: sliding down the slippery slope? In: Keown J, ed. Euthanasia examined. Cambridge: Cambridge University Press, 1995: ch 16.

4 Wal G van der, Maas PJ van der. Euthanasie en andere medische beslissingen rond het levenseinde. De praktijk en de meldingsprocedure. (Euthanasia and other medical decisions concerning the end of life. Practice and reporting procedure.) Den Haag: SDU uitgevers, 1996. For summaries of the research in English see Maas PJ van der. Euthanasia, physician-assisted suicide, and other medical practices involving the end of life in the Netherlands, 1990-1995. New England Fournal of Medicine 1996;335:1699; van der Wal G. Evaluation of the notification procedure for physician-assisted death in the Netherlands. New England fournal of Medicine 1996;335:1706.

5 See reference $4: 25$.

6 See reference 4 : tables $5.3 ; 6.2 ; 9.1$.

7 See reference 4 : table 5.5 .

8 Nederlands furistenblad 1994; $69 \mathrm{nr} 26: 895 \mathrm{ff}$. See also Jochemsen $\mathrm{H}$. The Netherlands experiment. In: Kilner JF et al, eds. Dignity and dying. Grand Rapids: Eerdmans, 1996: ch 12; Hendin H. Seduced by death: doctors, patients and the Dutch cure. New York: WW Norton, 1997: ch 2 .

9 Sorgdrager W, Borst-Eilers E. Euthanasie - De stand van zaken. Medisch Contact 1995;12: 381-4.

10 Kastelijn WR. Standpunt hoofdbestuur KNMG inzake euthanasie. Utrecht: KNMG, August 1995.

11 See reference 4: table 5.4.

12 See reference 4 : table 5.6.

13 See reference 4 : table 5.12 .

14 See reference 4 : table $6.2 ; 92$.

15 See reference 4 : table 6.5 .

16 This suggests a disturbing incidence not only of non-voluntary euthanasia but also of involuntary euthanasia.

17 See reference 4 : table 6.4 .

18 See reference 4: table 6.3.

19 See reference $4:$ table 6.6

20 See reference 4 : table 7.2 .

This figure is calculated from the researchers' percentages and estimates at pages 92-93. In fact the figure of 2,000 is conservative as it is derived from the total number of 20,000 cases yielded by the physician-interviews rather than from the larger total of 25,800 in the death certificate study. "Explicit" is the researchers' translation of the word "uitdrukkelijk". We think a more accurate translation would be "primary" as a purpose can be explicit yet secondary or primary yet implicit.

21 See reference 4: 93.

22 See reference 4 : table 7.4 .

23 See reference 4 : tables $7.3 ; 7.5$.

24 See reference 4 : tables $8.1 ; 8.3 ; 84$.

25 See reference 4 : tables $8.1 ; 8.3$.

26 See reference 4 : table 8.2 .

27 See reference 4: 189.

28 See reference 4: table 17.2.

29 The researchers' estimate of 15 cases may be traced to their observation that in $17 \%$ of cases in which drugs were administered with the explicit intent to shorten life (totalling 15 cases), one of the drugs administered paralysed muscles and therefore caused death almost immediately whereas in a majority of cases in which drugs were administered in combination with the withdrawal of treatment, the treatment withdrawn was artificial ventilation and the medication may have been administered to prevent suffocation.

30 See reference 4 : table 17.3 .

31 See reference 4: table 17.5 .

32 See reference 4 : table 18.1 .

33 See reference 8: Hendin: ch 2.

34 See reference 4 : table 10.1 .

35 See reference 4 : table 10.2 .

36 See text on page 19 immediately preceding reference 39 .

37 The reason for the discrepancy between the two totals might be a certain bias in the physicians' responses. The authors of the survey suggest that some of the physicians interviewed, when asked to discuss their most recent case of euthanasia, in fact discussed $a$ recent case which had a stronger impact, probably because it was reported. See reference 4: 113.

38 See reference 4 : 102-7.

39 See reference 4 : table 11.6 .

40 See reference 4 : table $11.8 ; 225$.

4114,200 of these cases involved no explicit request from the patient. In cases where the patient had refused treatment, the doctors could properly, had they wished, have omitted treatment for this reason and without intent to shorten life. Similarly, as was mentioned above, it is unclear in how many cases of non-treatment the treatment was in fact disproportionate and could properly have been withdrawn for that reason without the doctors resorting to an intention to shorten life.

42 See reference $4: 240$.

43 See reference $4: 144-5$.

44 See for example Angell $M$. Euthanasia in the Netherlands good news or bad? New England fournal of Medicine 1996;335: 1677.

45 See for example Gomez C. Regulating death. New York: Free Press, 1991; see reference 8: Hendin; see reference 3: Jochemsen; see reference 3: Keown.

46 While acknowledging this fact, Dr Angell suggests that doctors fail to report because they find the reporting procedure "burdensome" and "daunting". See reference 44: 1677. But it is difficult to see how the procedure - the filing of a report with the local medical examiner (another doctor) in the sure knowledge that if the guidelines have been followed there is no prospect of prosecution - can realistically be so described. Indeed, many doctors admit that they omit to report simply because they do not want the inconvenience of an investigation either for themselves or the family (see text at page 19 immediately preceding reference 40 ). 